\title{
Does Self-Esteem Mediates the Association Between Personality Traits and Happiness? A Structural Equation Modeling Approach
}

\author{
Nikolaos Tsigilis (Corresponding author) \\ Department of Journalism and Mass Media Communication, Aristotle University of \\ Thessaloniki, 46 Egnatia Str., 54625 Thessaloniki, Greece
}

Tel: 30-2310-991-997 E-mail: ntsigilis@jour.auth.gr

\section{Dalia Srebauite}

Department of Psychology, City College: An International Faculty of the University of Sheffield, 24 Proxenou Koromila Str., 54622 Thessaloniki, Greece

Tel: 30-2310-224-421 E-mail: dsrebaliute@city.academic.gr

Received: February 11, 2015 Accepted: April 2, 2015 Published: April 3, 2015

doi:10.5296/jsss.v2i2.7370 URL: http://dx.doi.org/10.5296/jsss.v2i2.7370

\begin{abstract}
The present study was set out to explore the association among self-report happiness, personality traits and self-esteem in the Greek cultural setting. In particular, it was examined the mediating role of self-esteem on the relation of extraversion, neuroticism and happiness. In the study participated 207 Greek adults aged 25-60 years old. Three different questionnaires were administered to all participants: the Oxford Happiness Questionnaire (OHQ), the Eysenck Personality Questionnaire Revised-Abbreviated (EPQR-A) and the Rosenberg Self-esteem Scale (RSE). Results indicated that the three constructs (self-esteem and two personality traits) jointly explained the $67 \%$ of happiness variability. Happiness is best predicted by self-esteem, following by neuroticism (negatively) and extraversion (positively). Moreover, structural equation model (SEM) analysis showed that self-esteem only partially mediated the effects of both extroversion and neuroticism on self-report happiness.
\end{abstract}

Keywords: Life satisfaction, Positive affect, Personality, Mediation, Structural equation modeling 


\section{Introduction}

Happiness is a global term reflecting people's judgments about the overall quality of their life-as-a-whole (Diener, 2000; Veenhoven, 1991). According to Deci and Ryan (2008) happiness refers to optimal psychological experience and functioning, and is what people think and feel about their lifes. A happy person is someone who is frequently cheerful, only seldom sad and feels satisfied with the conditions of her/his life (Lucas \& Diener, 2000). Psychologists in the field of well-being attempted to understand the determinants of happiness and to predict its levels (Argyle, 2001; Diener, Shu, Lucas, \& Smith, 1999; Eysenck, 1990; Seligman \& Csikszentmihalyi, 2000). Three independent components are usually suggested as facets of happiness: (a) cognitive beliefs about one's overall level of satisfaction, (b) frequency of positive affect (pleasant moods and emotions), and (c) absence of negative affect (unpleasant moods and emotions) (Hill \& Argyle, 2002; Lucas, Diener, \& Suh, 1996; Myers \& Diener, 1995). Past studies suggest that all three components of happiness are influenced by individuals' personality and by the cultural context in which the individual is embedded (Diener, Diener, \& Diener, 1995).

Various existing theories and models attempted to explain happiness. Bottom -up and top -down theories are two perspectives which provide the most comprehensive portrayal of happiness (Diener, Scollon, Oishi, Dzokoto, \& Suh, 2000). A bottom -up theory emphasizes on external factors such as income, job, physical health, educational attainment and personal relationship as well as gender, age, marital status or race in perception of happiness. Studies have shown that these determinants affect person's happiness but do not always have an enduring impact (Diener Oishi, \& Lucas, 2003; Lyubomirsky, King \& Diener, 2005). An alternative view, top-down, holds that internal factors such as personality traits in long term happiness seemed to be stable and influence individuals' happiness (Lykken \& Tellegen, 1996). Thus, the top-down theory supports the notion that happiness is caused from the "inside" rather than "outside" and concentrates on biological and psychological factors that direct cognitions and behaviors of individual (Diener et al., 1999; Lyubomirsky et al., 2005). Both these theories attempt to explain individuals' happiness and suggest that personality as well as objective factors (e.g. physical health, marital status) account in happiness outcomes, but to a different extent (Diener, 2000; Lyubomirsky et al., 2005).

\subsection{Personality Traits and Happiness}

Prior research supported the importance of personality traits in determining experienced levels of happiness (DeNeve \& Cooper, 1998; Diener \& Diener, 1995; Fransis, 1999; Lucas \& Fujita, 2000; Lykken \& Tellegen, 1996; Lynn \& Steel, 2006). Personality traits describe individuals' propensities toward stable patterns of thoughts, feelings, and actions that are consistent across situations and across life span (McCrae, 2002). With regard to the top-down theory, studies of happiness and personality have shown the significance of personality traits on happiness (Eysenck, 1990). Studies on twins examined the heritability of happiness and found that about $80 \%$ of the variance in long-term of happiness could be attributed to in-inborn temperament (Lykken \& Tellegen, 1996). However, other authors argued that these findings seems too extreme, yet they maintain that even when heritability is known to be 
stable there would still be possibility for change (Lucas \& Diener, 2000).

In terms of the widely used Five-Factor Model, the traits extraversion and neuroticism have received the most theoretical attention, research and popularity in relation with happiness (DeNeve \& Cooper, 1998; Lucas \& Diener, 2000; McCrae, 2002). According to Eysenck (1990) these two traits are independent and biologically based personality factors and the most robust predictors of happiness. Of the theories that have been presented in the literature, most acknowledge that activities, sociability, warmth and optimism constitute important first order characteristics of extraversion (Eid, Reimann, Angleitner, \& Borkenau, 2003; Lucas \& Fujita, 2000; McCrae, 2000; Tkach \& Lyubomirsky, 2006). People who like themselves, who have positive beliefs about the future and who are sociable tend to be happier in their lives (Argyle, 2001; Argyle \& Lu, 1990a). In contrast, neuroticism is linked with negative affect, emotional reactivity, anxiety and low self-esteem (Carver, Sutton, \& Scheier, 2000; Lucas \& Fujita, 2000; Lynn \& Steen, 2006). Therefore, it is not surprising that empirical data consistently showed that extraversion and neuroticism significantly related and reliably predicted levels of happiness (DeNeve \& Cooper, 1998; Lyubomirsky et al., 2005).

\subsection{Self-esteem and Happiness}

Self-esteem refers to individuals' sense to their worth or how they appreciate, like or prize their selves (Baumeister, Campbell, Krueger, \& Vohs, 2003; Katz, 1998; Neto \& Mullet, 2004). Self-esteem is the most commonly studied personality concept in psychology and has been examined from various perspectives such as biological, socioeconomic and cultural factors (Naderi, Abdullah, Aizan, Sharir, \& Kumar, 2009; Neiss, Sedikides, \& Stevenson, 2002).

The existing body of literature seems to suggest that self-esteem may be thought either as a personality trait or psychological (global) state. In particular, typical levels of individuals' trait self-esteem are stable over time and across situations, whereas their momentary experiences of state (global) self-esteem fluctuate on trait level (Crocker, Brook, Niiya, \& Villacorta, 2006). A significant number of studies have focused on whether individuals' level of trait self-esteem is high or low (Baumeister et al., 2003; Crocker \& Park, 2004). High self-esteem levels are linked with increased happiness and decreased emotional distress (Brown, Dutton, \& Cook, 2001). Individuals who have high self-esteem are likely to be more confident about their abilities, making new friends and coping with problems, thus they often reported that they are happy and satisfied with their lives (Brown \& Marshall, 2001; Katz, 1998). On the contrary, individuals with low self-esteem are thinking about themselves in negative ways, which thoughts cause painful filings, sadness and anxiety. They are less sociable and frequently avoid taking chances and trying new things due to they doubt that they will be successful (Baumeister et al., 2003; Crocker \& Park, 2004). Based on the above considerations and in line with prior research findings it is rationale to anticipate a strong effect of self-esteem on happiness (Cheng \& Furnham, 2003; Joshanloo \& Afshari, 2011).

\subsection{Cross-cultural Issues}

Cross-cultural literature suggests that culture not only affects levels of personal happiness but 
also it moderates the determinants that correlate with individuals' experiences of happiness as well (Diener et al., 1999; Uchida, Norasakkunkit, \& Kitayama, 2004). Resent findings indicate that the extent of the relation between self-esteem and happiness varies across nations. For example, Diener and Diener (1995) in their study of 31 countries found that self-esteem is more strongly correlated with happiness in Western cultures than Eastern ones. That is, self-esteem is less important to collectivists than individualists. Moreover, individual personality traits and national character are considered to be interrelated factors and both can reflect person's happiness (Diener et al., 2003; Suh \& Oishi, 2002). As a sequel, most cross cultural studies and especially in English speaking countries showed that happiness was significantly correlated with traits extraversion and neuroticism (Diener et al., 2003; Lynn \& Steel, 2006). On the other hand, only extraversion and not neuroticism predicted happiness in Japan (Cheng \& Furnham, 2001). It seems that the association between self-esteem, extraversion and neuroticism may vary across cultures. Thus, scholars studying happiness suggested that for a firm understanding of happiness need to be considered both personality and cultural values (Diener et al., 2000; Naderi et al., 2009; Sheldon et al., 2010; Suh \& Oishi, 2002). Despite the fact that several studies have been conducted in various countries, there is limited empirical data regarding the issue of happiness in Greece.

\subsection{Rationale and Purpose of the Present Study}

As previously mentioned, existing research consistently showed that personality traits and self-esteem are stable predictors of happiness (Schimmack, Oishi, Radharishnan, Dzokoto, \& Ahadi, 2002). It has also been suggested that self-esteem plays a mediatory role in the relationship between personality traits and perceived happiness (Chen \& Furnham, 2003; Joshanloo \& Afshari, 2011). The vast majority of these studies used either a hierarchical regression analysis (Joshanloo \& Afshari, 2011) or path analysis (Chen \& Furnham, 2003). However personality traits, self-esteem and happiness are latent constructs which are measured indirectly using specifically developed items. Thus more advanced statistical procedures, such as structural equation modeling, should be employed, which can capture both the extent to which items are good indicators of their corresponding factors as well as the association among the latent constructs. An important feature of the SEM over other multivariate techniques pertains to the fact that the latent constructs are defined by many observed variables, in which measurement error is taken into account. In result, latent factors are free of random or systematic measurement error (Bollen, 1989). Thus it is warrant to examine the mediation role of self-esteem using sophisticated statistical procedures which overcomes prior studies methodological shortcomings and allows researchers to better approximate human behavior.

The purpose of the present study was to examine the association between self-report happiness, personality traits (extraversion and neuroticism) and self-esteem in the Greek cultural context. In particular, the research aimed at testing whether self-esteem mediates the effects of extraversion and neuroticism on happiness, using advanced statistical procedures.

\section{Method}

\subsection{Participants}


The participants of this study were 207 Greek adults from a large city of Northen Greece, Thessaloniki. This convenience sample consisted of 138 females and 69 males. The criterions for an adult to participate in the study were: (a) to has been working for the past two years and (b) to be in the age range from 25- 60 years old. Participants' mean age was 35.8 years and $(S D=9.59)$.

\subsection{Measures}

Overall three different instruments were used for the data collection. These are described below.

\subsubsection{Happiness}

Happiness was assessed by the Oxford Happiness Questionnaire (OHQ; Hills \& Argyle, 2002). The OHQ is a unidimensional measurement which consists of 29- items. Some items are phrased positively (e.g., I feel that life is very rewarding) and others negatively (e.g., I don't feel particularly pleased with the way I am). Responses were given on a six- point Likert scale from agree (6) through to disagree (1). Prior studies reported adequate levels of OHQ's internal consistency (Hills \& Argyle, 2002; Robbins, Francis, \& Edwards, 2008).

\subsubsection{Personality Traits}

The Eysenck Personality Questionnaire Revised-Abbreviated (EPQR-A; Francis, Brower, \& Philipchalk, 1992) was used to assess personality traits. EPQR-A is a 24-item self-repot measurement consisting of four sub-scales of 6 items each: extraversion, neuroticism, psychoticism, and lie scale. Each item is assessed on a two point scale: Yes-No format.

In the present study only two of the four subscales were administered namely, extraversion (e.g., Are you a talkative person?) and neuroticism (e.g., Would you call yourself a nervous person?). This decision was based on past research evidence showing that these two independent personality traits can significantly predict happiness (Diener et al., 2000; Eysenck, 1990; Lischetzke \& Eid, 2006). In terms of internal consistency, the measurement developers reported satisfactory alpha coefficient, 0.82 for extraversion and 0.77 for neuroticism. However, prior research has shown that EPQR-A reliability tends to vary a lot when it translated into different languages (Katz \& Francis, 2000).

\subsubsection{Self-Esteem}

The Rosenberg Self-Esteem Scale (RSE; Rosenberg, 1965) is a widely accepted and used scale that provides a unidimensional assessment of global self-esteem. The instrument has been most popular measure because of its high validity and prominence in personality research (Quilty, Oakman, \& Risko, 2006). RSE elaborated individuals' global perception about their own worth by indicating their agreement to 10 statements including five positively (e.g., On the whole, I am satisfied with myself) and five negatively worded items (I feel I do not have much to be proud of). Responses were given on a four-point scale from strongly disagree (1) throughout to strongly agree (4). Item scores were summed such that larger values indicated greater self-esteem. Past studies demonstrated the good psychometric properties of RSE (Cheng \& Furnham, 2003; Hatcher \& Hall, 2009; Rosenberg, 1965). 


\subsection{Procedure}

One of the researchers approached Greek adults and asked them to participate in the study. Participants were inhabitants of Thessaloniki, the largest city of Northern Greece. Volunteers were contacted in person and informed about the purpose of the study. Questionnaires were presented in Greek (participants' native language). Prior their administration all instruments were translated from English into Greek employing the back translation procedure. Prior to the main study, a pilot study was conducted to investigate the adequacy of instruments translation.

Initially participants recorded their personal demographic data: names, age, gender, marital status and education level. Then they completed a series of self-report instruments that included measures of happiness, personality traits and self-esteem. Prior the instruments' completion, consent form was given to be signed and they were told that there is no right or wrong answer. Verbal and written instructions regarding the questionnaires were given to the participants. Average time to complete all questionnaires was approximately $15 \mathrm{~min}$. Individuals participated on a voluntary basis and were assured that responses would be kept confidential and used for research purposes only.

\subsection{Data Analysis Strategy}

Structural equation modeling procedures were used to examine the meditational role of self-esteem on the relationship between the two personality traits (neuroticism and extraversion) and perceived happiness levels. The advantage of this procedure over a series of regression analyses is that all equations are simultaneously conducted, thus reducing type I error. Mediation analysis was conducted in two steps. In the first step it was tested whether the independent variables (personality traits) could reliably predict the dependent variable (happiness scores) (model 1). In the next step it was examined the reduction of the relationship between the independent and the dependent variable when the mediator (self-esteem) entered into the model (model 2). A full mediation effect is demonstrated when the independent variable does not make a significant contribution to the prediction of the dependent variable after the effect of the mediator is taken into account; otherwise, mediation is regarded only partial.

Initially, the chi-square value was used to assess the fit of the data to the proposed model. However, given the inherent shortcomings of the chi-square (sensitivity to sample size and departures for normality) evaluation of the fit was supplemented by additional fit indices. These included the Comparative Fit Index (CFI), the Standardized Root-Mean-Square Residual (SRMR) and the Root Mean Squared Error of Approximation (RMSEA). According to the guidelines provided by $\mathrm{Hu}$ and Bentler (1999) values close to .06 for RMSEA and SRMR, and close to .95 for CFI suggest a relative good fit between the observed data and the postulated model.

Several authors seem to agree that item parceling is a beneficiary practice within the structural equation modeling framework (Bandalos, 2002; Bandalos \& Finney, 2001; Little, Cunningham, Shahar, \& Widaman, 2002; Nasser \& Takahashi, 2003). In particular, 
combining items into small groups of items within scales or subscales has been demonstrated to increase the stability of the parameter estimates, lead to a reduction in sampling error, improve the variable to sample size ratio and reduce the effects of non-normality. Moreover, residuals have fewer chances to be correlated. Given the relative small number of participants in relation to the number of observed variables and the binary response scale of the personality trait instrument it was decided to apply the item parceling practice. Thus, five item parcels were formed from the initial 29 items of the OHQ. Similarly, three item parcels were created to represent the self-esteem construct and two to represent the neuroticism and the extraversion personality traits (respectively). It should be noted that items were randomly selected to be aggregated.

\section{Results}

With regard to the first model, application of structural equation modeling procedures using AMOS ver. 18.0 showed an excellent fit of the data to the first model $\left(\chi^{2}=24.32, d f=24, p\right.$ $=.44, C F I=.998, R M S E A=.008, S R M R=.026$ ). Factor loadings ranged from .64 to .86 . As expected the two personality traits were negatively correlated $(r=-.46, p<.001)$. Moreover, neuroticism and extraversion jointly accounted for $49 \%$ of the happiness variability. Standardized regression coefficients suggested that neuroticism $(B=-.49, p<.001)$ was more important in predicting happiness than extraversion $(B=.32, p=.002)$.

The second model (model 2) examined the mediational effects of self-esteem on the relationship between personality traits and perceived happiness. All fit indices suggested the plausibility of the postulated model $\left(\chi^{2}=62.29, d f=48, p=.08, C F I=.987, R M S E A=.038\right.$, $S R M R=.033)$. Figure 1 depicts the factor loadings, correlations among the factors and the structural paths of model 2 . Both personality traits reliably predicted self-esteem scores $\left(R^{2}=.389\right)$. Whereas the structural path associated with neuroticism was statistically significant extraversion's structural path only marginally did not reached statistical significance $(B=.21, p=.058)$. 


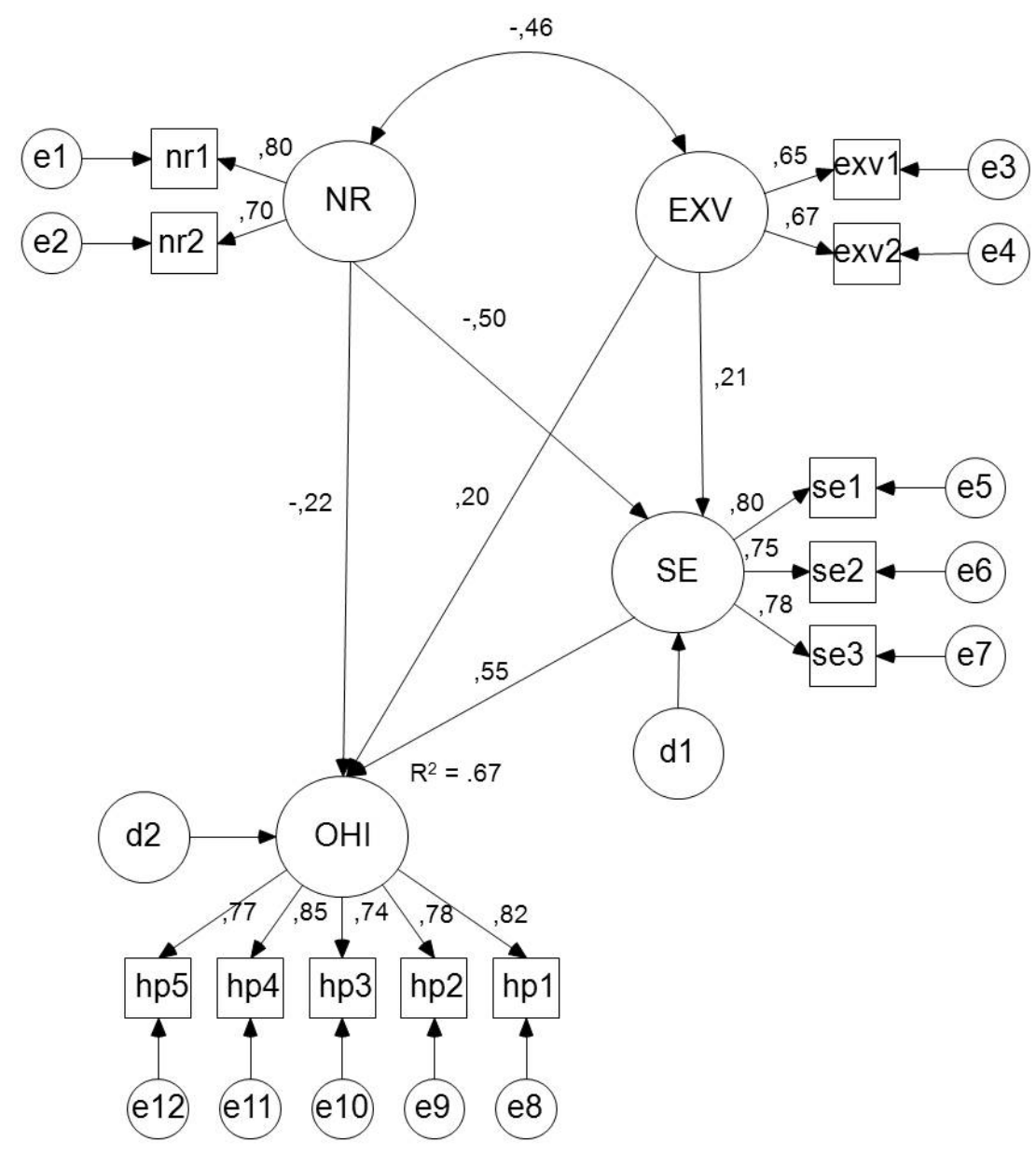

Figure 1. Mediation role of self-esteem on the relationship between happiness and selected personality traits

With regard to the perceived happiness scores, the three constructs jointly explained the $67 \%$ of its variability. Visual inspection of figure 1 clearly shows the reduction in the values of the regression coefficients from personality traits to perceived happiness (from -.46 to -.22 for neuroticism and from .32 to .20 for extraversion). Despite however the substantial reduction these coefficients remained statistically significant $(p=.017$ and $p=.021$ respectively) supporting the partial mediation effect of self-esteem.

\section{Discussion}

The present study was set out to examine the association between personality traits, self-esteem and happiness in the Greek cultural setting for which research on happiness is scarce. In particular, it was investigated the mediation role of self-esteem on extraversion, neuroticism and self-reported adult's happiness. Consistent with previous studies (Cheng \& Furnham, 2003; DeNeve \& Cooper, 1998; Francis, 1999) it was found that the two major personality traits and self-esteem were significant predictors of happiness and accounted for a considerable and meaningful amount of its variance. Structural equation procedures showed that personality traits have an effect on the levels of subjective happiness through self-esteem. 
Given that neuroticism had also a direct effect on happiness it was concluded that self-esteem partially mediates the relationship between personality traits and happiness. These findings are in line with prior research and provide additional evidence for the meditation role of self-esteem.

Findings from the current study showed that extraversion was positively correlated with levels of happiness. Some speculations have been offered that attempt to explain why extraverts tend to be happier than introverts. Extraverts seem to be more sociable and have bigger circle of friends. They have superior social skills and favorable life events as in domains of job and leisure (Argyle \& Lu, 1990b). Social engagement gives people an opportunity to make and enjoy relationships that are beneficial to emotional quality of life (Diener, 2000; Thach \& Lyubomirsky, 2006). According to Argyle and Lu (1990a) extraverts are happier because they are likely to be more confident, they think more positively about their abilities and skills, and feel more personal control which might lead them to experience greater positive affect. Also, Lucas, Le and Dyrenforth (2008) suggested that when extraverts and introverts participate in similar social activities introverts seemed to enjoy these activities less than extraverts do.

On the other hand neuroticism was negatively correlated with happiness and influenced it, both directly and indirectly through self-esteem. Interestingly, it was found neuroticism to be stronger predictor of happiness than extraversion. Although most previous studies reported that extraversion is a strongest predictor of happiness, our data do not support these results. People high in neuroticism are sensitive, nervous and recurrently experience more negative life events than less neurotic people do (Lischetzke \& Eid, 2006). Also, neurotics tend to be moody and have tendency to swing easily into anxiety, depression and hostility (Bolger \& Schilling, 1991). Since neuroticism includes negative affect seemed to be a great predictor of unhappiness (Burger \& Caldwell, 2000).

Consistent with the existing literature self-esteem was found to be one of the strongest predictors of self-report happiness (Diener et al., 2003; Lyubomirsky et al., 2006). The present study provides additional evidence suggesting that self-esteem does lead to greater happiness in the Greek cultural setting. Self- esteem is a concept that lies on general feelings of one's worth (Cast \& Burke, 2002; Katz, 1998). Happy people in their every day experiences tend to feel well about themselves, while people who lack self-worth or self -respect are usually unhappy (Richardson, Ratner, \& Zumbo, 2009). Moreover, happy people tend to report higher self-esteem levels and they think more optimistic (Neiss et al., 2009). Also, there is an agreement that self-esteem is important to many aspects of individual's life (Crocker et al., 2004; Lyubomirsky et al., 2006). For example, some research shows that high self-esteem is a protective factor and helps people to deal more effectively with their life stressors (Baumeister et al., 2003). Consistent with this, some mental health professionals suggested that increasing people levels of self-esteem can have many lasting benefits such as psychological well-being, social relationships and carrier success (Winstok \& Enosh, 2004). Indeed our results seem to support the positive influence of self-esteem on happiness. However, on the other hand this approach is questioned because encouraging people to exchange their self-esteem may cause more harm than good for example, boosting 
self-esteem may promote narcissism rather than desirable consequences (Baumeister et al., 2003). Obviously more research adopting an experimental design might provide useful evidence on the above controversy.

Finally, an issue needs to be further clarified. That is whether the mediation is full or partial needs to be addressed. Published studies are inconclusive since they reported mixed results. Whereas some studies suggest that self-esteem has a partial mediation role (Joshanloo \& Afshari, 2011) others reported a full mediation (Cheng \& Furnham, 2003; Kwan, Bond, \& Singelis, 1997). Findings from the present study seem to support the partial mediation role of self-esteem at least in the Greek cultural context.

The present study is not free of limitations and these should be considered when interpreting the findings. First, the relative small sample size and the convenience nature of its recruitment suggest a need for future studies to use a representative sample of the Greek population. Second the associations among personality characteristics, self-esteem and self-report happiness were examined using a specific pattern of links. However, the correlational design of the study does not allow for causal inferences about the way these concepts are connected. Lastly, individuals' responses might reflect personal or social desires rather than reality and lead to cliché answers. More specifically, self-report judgments may be affected by current mood, surrounding environment or by self-enhancing biases and influence levels of participants' happiness. Thus research efforts in the field of happiness could examine the extent to which social desirability influence participants' responses. Based on the above considerations the present findings should be regarded as indicative of the levels of subjective happiness levels in Greece and its association with self-esteem and personality traits.

Despite these shortcomings the present study has several strengths. This research makes a valuable contribution to existing body of knowledge in several ways. First, it offers a starting point for understanding happiness in the Greek cultural context. Employment and use of a well established measure of happiness, such as the Oxford Happiness Inventory, enables the comparison of perceptions about happiness in the Greek setting with those of other nations and cultural contexts. Second, an advantage of the present study over the previous ones is the implementation of advanced statistical procedures. The use of multivariate techniques to examine the complex pattern of associations results in a better approximation of human behavior. Thus researchers may have increased confidence on the derived findings. Future studies could move beyond in two ways: (a) by combining qualitative and quantitative approaches to better understand happiness and (b) by reporting the link among happiness and other potential predictors. Such studies might promote a deeper insight on the phenomenon of happiness and help people experience this amazing feeling.

\section{References}

Argyle, M. (2001). The psychology of happiness. London: Routledge.

Argyle, M., \& Lu, L. (1990a). The happiness of extraverts. Journal of Personality and Individual Differences, 11, 1011-1017. http://dx.doi.org/10.1016/0191-8869(90)90128-E 
Argyle, M., \& Lu, L. (1990b). Happiness and social skills. Journal of Personality and Individual Differences, 11, 1255-1261. http://dx.doi.org/10.1016/0191-8869(90)90152-H

Bandalos, D. L. (2002). The effects of item parceling on goodness-of-fit and parameter estimate bias in structural equation modeling. Structural Equation Modeling, 9, 78-102. http://dx.doi.org/10.1207/S15328007SEM0901_5

Bandalos, D. L., \& Finney, S. J. (2001). Item parceling issues in structural equation modeling. In G. A. Marcoulides \& R. E. Schumacker (Eds.), Advanced structural equation modeling: New developments and techniques. Mahwah, NJ: Lawrence Erlbaum Associates, Inc.

Baumeister, R. F., Campbell, J. D., Krueger, J. I., \& Vohs, D. K. (2003). Does high self-esteem cause better performance, interpersonal success, happiness, or healthier lifestyle? Journal of Psychological Science In The Public Interest, 4, 1-44. http://dx.doi.org/10.1111/1529-1006.01431

Bollen, K., A. (1989). Structural equations with latent variables. New York: Wiley. http://dx.doi.org/10.1002/9781118619179

Bolger, N., \& Schilling, E. A. (1991). Personality and the problems of everyday life: The role of neuroticism in exposure and reactivity to daily stressors. Journal of Personality, 59, 355-386. http://dx.doi.org/10.1111/j.1467-6494.1991.tb00253.x

Brown, J. D., Dutton, K. A., \& Cook, K. E. (2001). From the top down: self-esteem and self-evaluation. Journal of Cognition and Emotion, 15, 615-631. http://dx.doi.org/10.1080/02699930143000004

Brown, J. D., \& Marshal, M. A. (2001). Self-esteem and emotion: Some thoughts about feelings. Personality and Social Psychology Bulletin, 5, 575-584. http://dx.doi.org/10.1177/0146167201275006

Burger, J. M., \& Caldwell, D. F. (2000). Personality, social activities, job-search behavior and interview success: distinguishing between PANAS traits and positive affect and NEO extraversion. Journal of Motivation and Emotion, 24, 51-62. http://dx.doi.org/10.1023/A:1005539609679

Carver, C. S., Sutton, S. K., \& Scheier, M. F. (2000). Actions, emotions, and personality: emerging conceptual integration. Society of Personality and Social Psychology, 26, 741-751. http://dx.doi.org/10.1177/0146167200268008

Cheng, H., \& Furnham, A. (2003). Personality, self-esteem and demographic predictor of happiness and depression. Journal of Personality and Individual Differences, 34(6), 921-942. http://dx.doi.org/10.1016/S0191-8869(02)00078-8

Cheng, H., \& Furnham, A. (2001). Attributionl style and personality as predictors of happiness and mental health. Journal of Happiness Studies, 2, 307-327. http://dx.doi.org/10.1023/A:1011824616061

Crocker, J., Brook, A. T., Niiya, Y, \& Villacorta, M. (2006). The pursuit of self esteem: 
contingencies of self-worth and self-regulation. Journal of Personality, 74(6), 1649-1772. http://dx.doi.org/10.1111/j.1467-6494.2006.00427.x

Croker, J., \& Park, L. E. (2004). The costly pursuit of self-esteem. Psychological Bulletin, 3, 392-414. http://dx.doi.org/10.1037/0033-2909.130.3.392

Deci, E. L., \& Ryan,R. M. (2008). Hedonia, eudaimonia, and well-being: An introduction. Journal of Happiness Studies, 9, 1-11. http://dx.doi.org/10.1007/s10902-006-9018-1

DeNeve, K. M., \& Cooper, H. (1998). The happy personality: A meta-analysis of 137 personality traits and subjective well-being. Psychological Bulletin, 124(2), 197-229. http://dx.doi.org/10.1037/0033-2909.124.2.197

Diener, E. (2000). Subjective well-being: the science of happiness and a proposal for a national index. Journal of American Psychology, 55(1), 34-43. http://dx.doi.org/10.1037/0003-066X.55.1.34

Diener, E., Scollon, C. N., Oishi, S., Dzokoto, V., \& Suh, M. (2000). Positivity and the construction of life satisfaction judgments: Global happiness is not the sum of its parts. Journal of Happiness Studies, 1, 159-176. http://dx.doi.org/10.1023/A:1010031813405

Diener, E., \& Diener, M. (1995). Cross cultural correlates of life satisfaction and self-esteem. Journal of Personality and Social Psychology, 68, 653-663. http://dx.doi.org/10.1037/0022-3514.68.4.653

Diener, E., Diener, M. \& Diener, C. (1995). Factors predicting the subjective well-being of nations. Journal of Personality and Social Psychology, 69, 851-864. http://dx.doi.org/10.1037/0022-3514.69.5.851

Diener, E., Suh, E. M., Lucas, R. E., \& Smith, H. E. (1999). Subjective well-being: the three decades of progress. Psychological Bulletin, 125, 276-302. http://dx.doi.org/10.1037/0033-2909.125.2.276

Diener, E, Oishi, S., \& Lucas, R.E. (2003). Personality, culture, and subjective well-being: emotional and cognitive evaluations of life. Annual Reviews of Psychology, 54, 403-425. http://dx.doi.org/10.1146/annurev.psych.54.101601.145056

Eid, M., Riemann, R., Angleitner, A., \& Borkenau, P. (2003). Sociability and positive emotionality: genetic and environmental contributions to the covariation between different facets of extraversion. Journal of Personality, 71(3), 219-346. http://dx.doi.org/10.1111/1467-6494.7103003

Eysenck, H. (1990). Biological dimensions of personality. In Pervin, L. A. (Ed.), Handbook of personality: Theory and research (pp. 244-276). New York: Guilford.

Francis, L. (1999). Happiness is a thing called extraversion. Journal of Personality and Individual Differences, 26, 5-11. http://dx.doi.org/10.1016/S0191-8869(98)00185-8

Francis, L. J., Browen, L. B., \& Philipchalk, R. (1992). The development of an abbreviated form of the Revised Eysenck Personality Questionnaire (EPQR-A): Its use among students in 
England, Canada, the USA and Australia. Personality and Individual Differences, 13, 443-449. http://dx.doi.org/10.1016/0191-8869(92)90073-X

Hatcher, L., \& Hall, L. A. (2009). Psychometric properties of the Rosenberg self-esteem scale in Africa American single mothers. Issues in Mental Health Nursing, 2, 70-77. http://dx.doi.org/10.1080/01612840802595113

Hu, L., \& Bentler, P. M. (1999). Cutoff criteria for fit indexes in covariance structure analysis: Conventional criteria versus new alternatives. Structural Equation Modeling, 6, 1-55. http://dx.doi.org/10.1080/10705519909540118

Hills, P., \& Argyle, M. (2002). The Oxford Happiness Questionnaire: A compact scale for the measurement of psychological well-being. Journal of Personality and Individual Differences, 33(3), 1073-1082. http://dx.doi.org/10.1016/S0191-8869(01)00213-6

Joshanloo, M., \& Afshari, S. (2011). Big-five personality traits and self esteem as predictors of life satisfaction in Iranian Muslim university students. Journal of Happiness Studies, 12, 105-113. http://dx.doi.org/10.1007/s10902-009-9177-y

Katz, E. B. (1998). Self-esteem: the past of an illusion. The American Journal of Psychoanalysis, 58, 303-315. http://dx.doi.org/10.1023/A:1022539508799

Katz, Y. J., \& Francis, L. J. (2000). Hebrew Revised Eysenck Personality Questionnaire: short form (EPQR-S) and abbreviated (EPQR-A). Social Behavior and Personality, 28(6), 555-560. http://dx.doi.org/10.2224/sbp.2000.28.6.555

Kwan, V. S. Y., Bond, M. H., \& Singelis, T. M. (1997). Pancultural explanations for life-satisfaction: Adding relationship harmony to self-esteem. Journal of Personality and Social Psychology, 73, 1038-1051. http://dx.doi.org/10.1037/0022-3514.73.5.1038

Lischetzke, T., \& Eid, M. (2006). Why extraverts are happier than introverts: The role of mood regulation. Journal of Personality, 74(4), 1128-1161. http://dx.doi.org/10.1111/j.1467-6494.2006.00405.x

Little, T. D., Cunningham, W. A., Shahar, G., \& Widaman, K. F. (2002). To parcel or not to parcel: Exploring the question, weighing the merits. Structural Equation Modeling, 9, 151-173. http://dx.doi.org/10.1207/S15328007SEM0902_1

Lykken, D., \& Tellegen, A. (1996). Happiness is a stochastic phenomenon. Journal of Psychological Science, 7, 186-189. http://dx.doi.org/10.1111/j.1467-9280.1996.tb00355.x

Lynn, M., \& Steel, P. (2006). National differences in subjective well-being: the interactive effects of extraversion and neuroticism. Journal of Happiness Studies, 7, 155-165. http://dx.doi.org/10.1007/s10902-005-1917-z

Lyubomirsky, S., King, L., \& Diener, E. (2005). The benefits of frequent positive affect: does happiness lead to success? Journal of Psychology Bulletin, 131, 803-855. http://dx.doi.org/10.1037/0033-2909.131.6.803

Lucas, R. E., \& Diener, E. (2000). Personality and subjective well-being across the life span. 
In D. L. Molfese and V. J. Molfese (Eds.), Temperament and personality development across the life span (pp. 211-234). Hillsdale, NJ: Erlbaum.

Lucas, R. E., Diener, E., \& Suh, E. M. (1996). Discriminant validity of subjective well-being measures. Journal of Personality and Social Psychology, 71(3), 616-628. http://dx.doi.org/10.1037/0022-3514.71.3.616

Lucas, R. E., \& Fujita, F. (2000). Factor influencing the relation between extraversion and pleasant affect. Journal of Personality and Social Psychology, 6, 1039-1056. http://dx.doi.org/10.1037/0022-3514.79.6.1039

Lucas, R. E., Le, K., \& Dyrenforth, P. E. (2008). Explaining the extraversion/positive affect relation: Sociability cannot account for extraverts' greater happiness. Journal of Personality, 76, 385-414. http://dx.doi.org/10.1111/j.1467-6494.2008.00490.x

McCrae, R. R. (2002). Cross-cultural research on the five-factor model of personality. Online Reading in Psychology and Culture, Unit 4. http://dx.doi.org/10.9707/2307-0919.1038

Myers, D. G., \& Diener, E. (1995). 'Who is happy'? Journal of Psychological Science, 6, 10-19. http://dx.doi.org/10.1111/j.1467-9280.1995.tb00298.x

Naderi, H., Abdullah, R., Aizan, H. T., Sharir, J., \& Kumar, V. (2009). Self-esteem, gender, and academic achievement of undergraduate students. American Journal of Scientific Research, 3, 26-37.

Nasser, F., \& Takahashi, T. (2003). The effect of using item parcels on ad hoc goodness-of-fit indexes in confirmatory factor analysis: An example using Sarason's Reactions to Tests. $\begin{array}{lllll}\text { Applied Measurement in } \quad \text { Education, } & \text { 16, }\end{array}$ http://dx.doi.org/10.1207/S15324818AME1601_4

Neiss, M. B., Sedikides, C., \& Stevenson, J. (2002). Self-esteem: a behavioral genetic perspective. European Journal of Personality, 16, 351-367. http://dx.doi.org/10.1002/per.456

Neto, F., \& Mullet, E. (2004). Personality, self-esteem, and self-construal as correlates of forgivingness. European Journal of Personality, 18, 15-30. http://dx.doi.org/10.1002/per.500

Quilty, L. C., Oakman, J. M., \& Risko, E. (2006). Correlates of the Rosenberg Self-esteem Scale method effects. Structural Equation Modeling, 13, 99-117. http://dx.doi.org/10.1207/s15328007sem1301_5

Richardson, C. G., Ratner, P. A., \& Zumbo, B. D. (2009). Further support of multidimensionality within the Rosenberg self-esteem scale. Journal of Current Psychology, 28, 98-114. http://dx.doi.org/10.1007/s12144-009-9052-3

Robbins, M., Francis, L. J., \& Edwards, B. (2008). Prayer, personality and happiness: A study among undergraduate students in Wales. Mental Health, Religion \& Culture, 11(1), 93-99. http://dx.doi.org/10.1080/13674670701702548

Rosenberg, M. (1965). The association between self-esteem and anxiety. Psychiatric Reserves, 1, 135-152. http://dx.doi.org/10.1016/0022-3956(62)90004-3 
Schimmack, U., Oishi, S., Radhakrishnan, P., Dzokoto, V., \& Ahadi, S. (2002). Culture, personality, and subjective well-being: integrating process model of life satisfaction. Journal of Personality and Social Psychology, 4, 582-593. http://dx.doi.org/10.1037/0022-3514.82.4.582

Seligman, M. E. P., \& Csikszentmihalyi, M. (2000). Positive psychology. American Psychologist, 55, 5-14. http://dx.doi.org/10.1037/0003-066X.55.1.5

Sheldon, K. M., Abad, N., Ferguson, Y., Gunz, A., Houser-Marko, L., Nichols, C. P., \& Lyubomirsky, S. (2010). Persistent pursuit of need-satisfying goals leads to increased happiness: A 6-month experimental longitudinal study. Motivation and Emotion, 34, 39-48. http://dx.doi.org/10.1007/s11031-009-9153-1

Suh, E. M., \& Oishi, S. (2002). Subjective well-being across cultures. Online reading in psychology and culture, Unit 10. http://dx.doi.org/10.9707/2307-0919.1076

Tkach, C., \& Lyubomirsky, S. (2006). How do people pursue happiness? relating personality, happiness- increasing strategies and well-being. Journal of Happiness Studies, 7, 183-225. http://dx.doi.org/10.1007/s10902-005-4754-1

Uchida, Y., Norasakkunkit, V., \& Kitayama, S. (2004). Cultural constructions of happiness: theories and empirical evidence. Journal of Happiness Studies, 5, 223-239. http://dx.doi.org/10.1007/s10902-004-8785-9

Veenhoven, R. (1991). Is happiness relative? Journal of Social Indicators Research, 24, 1-34. http://dx.doi.org/10.1007/BF00292648

Winstok, Z., \& Enosh, G. (2004). Towards re-conceptualization of global self-image: preliminary findings of the validity and reliability of a structured scale. Journal of Individual Differences Research, 2, 63-80.

\section{Copyright Disclaimer}

Copyright reserved by the author(s).

This article is an open-access article distributed under the terms and conditions of the Creative Commons Attribution license (http://creativecommons.org/licenses/by/3.0/). 